This is a self-archived version of an original article. This version may differ from the original in pagination and typographic details.

Author(s): Serin, Hanife

Title: Non-abusing mothers' support needs after child sexual abuse disclosure : A narrative review

Year: 2018

Version: Accepted version (Final draft)

Copyright: (c) 2018 John Wiley \& Sons Ltd

Rights: In Copyright

Rights url: http://rightsstatements.org/page/InC/1.0/?language=en

Please cite the original version:

Serin, H. (2018). Non-abusing mothers' support needs after child sexual abuse disclosure : A narrative review. Child and Family Social Work, 23(3), 539-548.

https://doi.org/10.1111/cfs.12455 


\begin{abstract}
The role of maternal support has been perceived as vital throughout the recovery process of sexually abused children. However, it is important to look at the concept "support" from the perspective of non-abusing mothers' personal needs. This narrative review of the literature aimed to find out how non-abusing mothers' need for support in their responses to disclosure of child sexual abuse has been recognised. A comprehensive search on XXX university library interface yielded 12 academic articles based on empirical research. These articles were selected from those considered to have sufficiently investigated support for non-abusing mothers and included a mixture of qualitative, quantitative and mixed-method research. The data consisted of peer-reviewed online articles published in English between 2000 and 2017. Four themes emerged from the thematic analysis: improving the quality of the whole social support network for non-abusing mothers; being blamed, maternal guilt and shame; anger; and coping strategies. The findings show that the support needs of non-abusing mothers are usually explained based on their interaction with sexually abused children. However, it is necessary to listen to women's needs independently of their mothering role. If these mothers are better understood, not only they, but also their children, could be empowered.
\end{abstract}

Keywords: Sexual Abuse (Impact on Children and Adults), Mothering, Social Support, Domestic Violence, Violence (Against Women and Children) 


\section{Non-abusing Mothers' Support Needs after Child Sexual Abuse Disclosure: A Narrative \\ Review}

\section{Introduction}

Child sexual abuse (CSA) is a prevalent and usually hidden social problem, but awareness of it has been rising throughout the world. According to the statistics of the World Health Organisation, one in five women and one in thirteen men has been sexually abused in their childhood (WHO 2015). Furthermore, two recent meta-analyses reported similar estimates of CSA prevalence worldwide of 18-20\% for women and $8 \%$ for men (Pereda et al. 2009; Stoltenborgh et al. 2011). The aim of this narrative review was to find out how non-abusing mothers' own need for support following their initial responses to CSA disclosure has been recognised in the literature.

Previous reviews have addressed diverse topics such as mother blaming in intrafamilial CSA (Ehrmin 1996; Tamraz 1996; Crawford 1999), reactions of non-abusing parents after CSA disclosure (Elliot and Carnes 2001), the relationship between caregiver support for the child and CSA disclosure or the child's post disclosure functioning (Lovett 2004; Bolen and Gergely 2015), intervention and treatment (Womack 1999; Toledo and Seymour 2013), reconceptualisation of guardian support (Bolen 2002a) and factors affecting maternal response (Knott and Fabre 2014). However, this review differs from the above in drawing attention to non-abusing mothers' experiences of support for themselves associated with their responses to CSA disclosure.

It is necessary to briefly explain the main concepts used in this review. "Non-abusing" refers to a caregiver not accused of committing a crime against a child, such as physical or sexual abuse. 
"Disclosure", telling someone about an abuse situation, is the most significant first step towards stopping the abuse. The recipients of disclosure can vary: for example, they may be a friend, an adult or a professional (Alaggia, 2004). Additionally, "support needs" refers to nonabusing mothers' personal needs for support covering both formal and informal support. Formal support is defined as support services of any kind received from school, social services, court, police or health services whereas informal support refers to support from family, friends or other community members in the non-abusing mothers' close environment (see Starzynski et al. 2005).

CSA disclosure enhances the likelihood of both the abused children and non-abusing family member(s) receiving support throughout the recovery process. Parents, usually mothers, are the adults that children usually trust and quite frequently disclose to (Paine and Hansen 2002; Jensen et al. 2005). Non-abusing mothers usually go through a crisis after CSA disclosure. However, the focus is usually on the treatment of the abused child and judgment of the abuser rather than the needs of the mother (Kilroy et al. 2014). Although the child's perspective after disclosure and provision of support for the child is important, it is also important to study needs and support from the mother's perspective.

\section{Methodology}

This paper presents the findings of a narrative literature review (see Mays et al. 2005) of academic articles concerning non-abusing mothers and disclosure of their child's sexual abuse. The literature search was conducted on XXX University Library user interface XX on 13.10.2017 using 'Advanced Search' from 'International e-materials'. This was opted for as the aim was to find e-articles from various international databases. The key words 'mother*' 
was searched for in all fields AND 'support*' AND 'child* sex* abus*' were searched in abstracts. The reason that the keyword 'mother*' was searched in all fields was to maximize the chance of locating research utilising other concepts such as 'caregiver, caretaker and parent' in the publication title.

In all, 2901 online documents encompassing e-articles, dissertations, newspaper articles, reviews, books and conference proceedings written in different languages were found. The total number of articles was reduced to 760 after limiting the search results to peer-reviewed online full-text articles published in English between 2000 and 2017. This result was obtained from various databases including ProQuest Central, Social Sciences Citation Index (Web of Science), ASSIA: Applied Social Sciences Index and Abstracts, ERIC, Taylor \& Francis Online, Sage Publications and Science Direct (Elsevier).

The results were listed according to relevance, and the most relevant 250 articles were reviewed. The title, aim and abstract of each study were first meticulously read. If the abstract was not deemed sufficiently informative, the results section was also read paying specific attention to information related to support needs of non-abusing mothers. The articles without information on the topic were excluded. Furthermore, the studies using a sample of both children and parents were evaluated, and those providing sufficient information on non-abusing mothers were considered while only child-focused ones were not. At the end of this stage, 12 articles were selected for more careful analysis. The steps of the review process are visualised in Figure 1.

The selected 12 articles were divided into two categories based on their participants. In seven studies, the samples comprised non-abusing mothers only while the remainder encompassed 
non-abusing mothers, fathers or other adults with the principal responsibility for caregiving. In the 12 studies, non-abusing mothers made up the overwhelming majority of the research participants. The reviewed studies were conducted by researchers in the fields of social work, psychology and health sciences. Further information is presented in Table 1.

Thematic analysis was applied after selection of the relevant articles. This method is the bestknown one in narrative reviews and aims to produce a rudimentary synthesis of the findings while seeking to identify and compile the most significant issues in a body of literature (Mays et al. 2005).

According to Finfgeld-Connett and Johnson (2012), the way a qualitative systematic review is analysed depends on its purpose. For instance, the data analysis tends to be more linear if summative or aggregative perspectives are adopted whereas it is more iterative in reviews aiming at knowledge building or theory development. The main goal of this review is not the generation of concepts or theory. This paper is synthesised based on aggregation of the findings, and hence comparison among the selected studies is made only when applicable.

The reviewed studies have various limitations including limited sample size, analytic issues, clinical populations, retrospective self-report measures, lack of standardised measures investigating perceived maternal support (both formal and informal support from the perspective of non-abusing mothers), lack of generalisability of the results in qualitative research, selection bias and difficulty in measuring support overall. Despite these, the focus of this review can be considered innovative in the sense that it encourages future researchers to further discuss and work on the support needs of non-abusing mothers of sexually abused children. 
[Original location of Figure 1 is here]

[Original location of Table 1 is here] 


\section{Findings}

The analysis of the articles concentrates on how the previous research links non-abusing mothers' own support needs to their responses to CSA disclosure. The four themes derived from the review are improving the quality of the whole social support network for non-abusing mothers; being blamed, maternal guilt and shame; anger; and coping strategies. Although these themes are differentiated into four groups, they should not be understood as bounded but rather as intertwined with each other.

Improving the quality of the whole network for non-abusing mothers emerged as one of the broadest themes. Social support network is adopted as an umbrella term covering both the formal and informal support non-abusing mothers personally receive. One sub-theme is the quality of the relationship between non-abusing mothers and service providers (formal support) and another is informal support.

In a Canadian qualitative study, Alaggia (2001) investigated ten non-abusing mothers' responses in intrafamilial CSA cases in relation to their cultural context. The mothers' cultural and socioeconomic background was diverse in such aspects as race, ethnicity and religious affiliation. In this research, three themes, labelled "culture and religion", "cultural beliefs about preserving the family unit" and "value system conflicts between the mothers and service providers", were discovered. The mothers regarded as "less supportive", based on caseworkers' evaluation of their relationship with their sexually abused child, stated that social service professionals misunderstood, judged and isolated them. Forty per cent of the mothers reported that their caseworkers failed to understand their views concerning their remaining in contact with their abusive partners. These mothers, who showed strong adherence to cultural or religious beliefs and value systems, felt ignored by professionals. In contrast, the mothers in the "supportive" group reported having positive experiences and receiving beneficial information in support group sessions. 
Whereas Alaggia (2001) studied the views of both professionals and non-abusing mothers, Kilroy et al. (2014), in Ireland, qualitatively investigated 13 parents' perceptions of CSA disclosure and its impact on them. Utilising grounded theory analysis, eight categories emerged from the data. One of these was "support systems", encompassing family, friends, school, work, social services and other professional services. The authors pointed out that these avenues were described as the strongest variables ameliorating the deleterious effects of CSA on non-abusing parents and that the parents' perceptions revealed diverse reactions towards these parties.

According to the parental self-reports in Kilroy et al. (2014), professionals were usually unsupportive and lacking in knowledge, empathy and resources. Despite this dissatisfaction with most service providers, it is vital to remember that the study by Kilroy et al. (2014) was conducted within a specialised CSA unit and that many parents reported feeling satisfied with and empowered by the services provided in the unit, an outcome similar to that was reported by Alaggia (2001) for the group of supportive mothers, who had positive relations with service providers.

The findings of Dyb et al. (2003) contradict the conclusion of Kilroy et al. (2014) that support from the close environment and professionals heals the negative impact of CSA on caregiving adults. Dyb et al. (2003) worked with 39 parents (of whom 24 were mothers) and looked at how parents described stressful events and secondary life changes after alleged CSA cases at a day care centre. They hypothesised that non-abusing parents who received a higher level of social support from family, friends and their colleagues would have lower post-traumatic stress disorder (PTSD) symptoms than those receiving a lower level of social support. Using semi-structured interviews and self-reports, they found that social support was not a predictor of parental distress. They concluded, however, that the reason for this result could be too low a level of support or support that was not sufficiently comforting for non-abusing parents. 
Another study conflicting with Kilroy et al. (2014) is that by Cyr et al. (2013). Among other variables, Cyr and colleagues studied self-reported social support among 226 mothers registered via child protection services. Cluster analyses were conducted on various maternal characteristics such as PTSD symptoms, anger, avoidant coping and relations with the birth family. They aimed to find out if maternal profiles affected the mothers' ability to support their child. A preliminary analysis related to perceived social support revealed no significant differences among the mothers. Hence, this variable was excluded in their further analyses in which mothers were grouped as resilient, avoidant coping, traumatized and anger-oriented reactive. The authors suggested that future research should include support of the non-abusing partner and social, medical and judicial services, as their study only addressed the number of persons who could potentially offer support. Moreover, the study used social support measures to find out if mothers' ability to support their abused child was affected, whereas the impact of receiving social support on mothers' coping skills was overlooked.

Research investigating maternal needs also yields information on maternal expectations from service providers. The study by Toledo and Seymour (2016) in New Zealand focused on the impact of CSA disclosure on families and their needs afterwards. They studied 59 families in which $70 \%$ of the caregivers were non-abusing mothers. Mixed methods were adopted, involving various scales and open-ended questions for determination of the caregivers' needs. The results showed that they would have liked to learn better ways of coping with their children's problems and behaviour, and to gain knowledge on the indicators of CSA, how to communicate effectively with their children and how to respond appropriately to CSA after disclosure. Unlike Kilroy (2014), this study also included 62 children as participants. The caregivers' needs, therefore, were mostly identified in relation to their care of their children rather than their personal needs. The latter were limited to the desire of being listened to, relieving distress and having a safe space to reflect on feelings and thoughts (Toledo and Seymour 2016). 
The findings of Alaggia (2001), Kilroy and colleagues (2014), and Toledo and Seymour (2016) are supported by those of Han and Kim (2016) conducted in South Korea. They investigated the views of five professionals working in government agencies and four non-abusing mothers (as service recipients) of sexually abused children about what family programmes were needed. Analysis of focus group interviews yielded four categories, two of which were empathy from therapists and emotional support for mothers. The former was contributed solely by mothers whereas the latter was stated by both service providers and mothers. The need of empathy for non-abusing mothers has been indicated by various researchers. For instance, Kilroy et al. (2014) confirmed the importance of empathy emphasising that mothers expect professionals to develop a relationship based on empathy, Toledo and Seymour (2016) stated that mothers need to be listened to, and Alaggia (2001) drew attention to value system conflicts, including judgement, isolation and misunderstanding, between non-abusing mothers and professionals.

Other studies also point to the importance of the support that mothers receive from others, if only as an interpretation of findings. For example, Pretorius et al. (2011) in a study conducted in South Africa explored the experiences of three mothers whose children had been sexually abused by their male partners. Phenomenology was the approach adopted for analysing the data collected via openended interview questions. Significant themes found were shock, disbelief, anger, guilt, depression, loss of trust and blame. The authors remarked that the level of received support by mothers is clearly not sufficient following CSA and there is a need of conducting further research addressing social support in more detail especially in the context of clinical environments. The sample resembled those of Alaggia (2001), Kilroy et al. (2014) and Toledo and Seymour (2016), who also selected their participants from clinical environments, while the findings on perceived level of support varied across these studies. 
McCallum (2001) and Mayekiso and Mbokazi (2007) conducted qualitative research with nonabusing mothers via child protection agencies. The former was a case study with a sample of three women only and themes were derived by applying grounded theory. The latter included seven women and utilised thematic content analysis. Both indicated that mothers were not listened to and had to cope with being blamed by family or community members for not taking the necessary steps immediately or even for lying about the abuse. Moreover, both studies emphasised the secondary traumatisation mothers experienced from abusers, community members, professionals and the justice system. McCallum (2001) further stated that the mothers perceived professionals as forcing and judging them, keeping the power to themselves, and being distant and unsupportive, in line with the findings of Kilroy et al. (2014) and Toledo and Seymour (2016).

The findings of Levenson et al. (2012), Kilroy et al. (2014), Masilo and Davhana-Maselesele (2016) and Toledo and Seymour (2016) on caregivers' experiences on informal support parallel each other. Levenson et al. (2012) conducted a quantitative study using online surveys with 31 caregivers (of whom 26 were women) via four websites providing support for non-abusing family members. They discovered that over $50 \%$ of the participants perceived not being understood by their family and friends. Similarly, Kilroy et al. (2014) emphasised that family members and friends were perceived as unsupportive, for example blaming, judging, dismissing, avoidant, lacking or distant. Participants also reported having communication problems with their partners or spouses. Similarly, Toledo and Seymour (2016) indicated that non-abusing caregivers faced emotional problems and had uneasy relationships with their extended family members, especially when the abuse was intrafamilial.

The mothers studied by Masilo and Davhana-Maselesele (2016) found more divergent views on familial support. The authors conducted a qualitative study to explore maternal experiences after CSA among 17 non-abusing mothers registered via care centres helping sexually abused children in 
South Africa. The mothers had a close relationship with the abusers and all the cases were intrafamilial. They reported two different groups of intimate family members: one group was supportive while another was opposed to the sentencing of the perpetrator. Despite various reactions from intimate family members, other parties such as neighbours and teachers were willing to support both the mothers themselves and their children when needed. The mothers also expressed the need for support groups to be able to share their experiences with others facing similar issues.

Carvalho et al. (2009) conducted a qualitative study in Brazil to understand the perceptions of nonabusing mothers whose daughters had been sexually abused and they discovered the maternal need for informing and empowering the whole social support network. Ten mothers, registered via a governmental organisation helping sexually abused children, participated in semi-structured interviews. The authors criticised society for acting inadequately in helping the mothers to deal with their dilemmas related to their motherhood, family relations and sexual identity in intrafamilial cases. Moreover, they pointed out that the mothers' conflicts are usually based on the necessity of giving up their needs to meet their family needs. They emphasised that society at large fails to understand that certain roles are imposed on women whether or not they have the relevant resources and power. Other studies confirm that mothers can feel powerlessness, emotional pain, depression, suicidal ideation and secondary victimisation and that these issues are likely to negatively affect their coping strategies (McCallum 2001; Mayekiso and Mbokazi 2007; Masilo and Maselesele 2016; Pretorius et al. 2011).

Being blamed, maternal guilt and shame was the second theme that emerged from reviewed studies. This seems closely related to mothers' perceptions of themselves as incompetent protectors of their children and their feeling responsible for what has happened. Self-blame or shame might occur due to not being aware or ignoring the warning signs of the abuse (McCallum 2001; Mayekiso and Mbokazi 
2007; Pretorius et al. 2011). Carvalho et al. (2009) similarly emphasise that guilt emerges as a cultural factor associated with "the perfect motherhood myth" under the impact of patriarchal norms imposed by society. In the search for the guilty party, mothers unconsciously blame themselves for their child's abuse experience and thereby sustaining "the myth of the imperfect mother".

Alaggia (2001) states that mothers experience value conflicts due to feeling obliged to keep their family intact even in the presence of intrafamilial CSA and that this happens especially when they adhere to religious beliefs based on strict patriarchal norms that do not accept divorce (Alaggia 2001). Although not overtly explained as maternal guilt, self-blame or shame, it might be that cultural factors, such as obedience to religious precepts, limit mothers' agency by inducing feelings of shame or self-blame. Kilroy et al. (2014) explain non-abusing mothers' self-blame as due to a feeling of failure over not being able to stop the abuse, not being able to protect the child or not spotting the signs of abuse. However, they also found that although some parents felt responsible for what happened, others were aware that it was not their fault and that it was not possible to control everything in life.

Han and Kim (2016) demonstrated that feelings of shame or self-blame were among the most prominent feelings of non-abusing mothers, a finding that was also confirmed by service providers who were meeting sexually abused children in therapy sessions. Levenson et al. (2012) found that many caregivers reported guilt, shame or embarrassment about the abuse, comparable to the findings of Masilo and Davhana-Masalesele (2016) in which similar feelings, such as guilt and self-blame, were subsumed under the category labelled "emotional and psychological reactions".

Anger, as a reaction to negative attitudes of people in the mothers' environment, is the third theme found in this review. The mothers also felt anger towards themselves, which they associated with being blamed by others, and self-blame. The participants in McCallum (2001) were limited to three 
non-abusing mothers. However, anger emerged as reaction associated with other factors such as mother blaming, shock, denial and acceptance. Mayekiso and Mbokazi (2007), Han and Kim (2016) and Masilo and Davhana-Maselesele (2016) obtained similar results to those of McCallum (2001), demonstrating a relationship between maternal guilt and anger.

Mayekiso and Mbokazi (2007) found that mothers' anger was associated with feelings of guilt. The mothers questioned their decision-making abilities, their reasons for choosing an abusive partner and living with him even after CSA disclosure. More recent studies are consistent with the outcomes of Mayekiso and Mbokazi (2007). For instance, Han and Kim (2016) and Masilo and DavhanaMaselesele (2016) highlighted the association of anger with guilt and self-blame. Masilo and Davhana-Masalesele (2016) further noted that non-abusing mothers expressed anger towards themselves as they felt irresponsible in not being able to stop the sexual abuse, an observation in line with the views of the therapists in the study of non-abusing mothers of sexually abused children by Han and Kim (2016).

The non-abusing parents in the research by Kilroy and colleagues (2014), expressed anger towards their family members, who usually blamed, dismissed or evaded from talking about the problem, while friends were reported as being distant or missing or unwilling to share this private experience with them. Apart from reported anger towards the family members and perceived absence of support from friends, the non-abusing parents also felt anger toward the police, the legal system and school for various reasons, such as not taking necessary steps related to prosecution of the perpetrator, failing to give professional advice or not protecting the child (Kilroy et al. 2014). The finding of anger directed by non-abusing mothers towards service providers is not reported by Kilroy et al. (2014) alone. Mayekiso and Mbokazi (2007) also found that, because they felt blamed or not sufficiently supported, mothers expressed anger towards professionals. 
It is widely observed that maternal anger can be directed to different parties, including abusers and sexually abused children. According to Levenson et al. (2012), as many as $80 \%$ of non-abusing parents continued to express anger towards the abuser at the time the study was conducted. It is noteworthy that $42 \%$ of the non-abusing parents in their study were the abuser's spouse. In common with Levenson et al. (2012), Mayekiso and Mbokazi (2007) and Pretorius et al. (2011) also emphasise that anger was usually directed to the abuser partners of the non-abusing mothers.

Mothers' anger was also directed at children. Twenty-four percent of the mothers reported feelings of anger towards their sexually abused child (Levenson et al. 2012). In contrast, Cyr et al. (2013) found that resilient mothers (comprising one third of all participants) were not angry with their child, although in line with Levenson et al. (2012), they were angry with the abuser. The relationship between anger-oriented mothers and their sexually abused children was ambivalent in that the mothers were supportive but simultaneously angry with them (Cyr et al. 2013).

The last theme, named as coping strategies, consists of religion, avoidance, social isolation and improving knowledge on parenting and on the effects of CSA. Some studies point to the effects of religion on non-abusing mothers. For these mothers, religion was a comforting factor bringing relief from the overwhelming effects of CSA (Alaggia 2001; Masilo and Maselesele 2016). Religion was also utilised for projecting the overhelming emotions, such as anger and maternal guilt, experienced after CSA disclosure (Kilroy et al. 2014; Masilo and Maselesele 2016).

Cyr et al. (2013) used avoidant coping (seeking to escape dealing with the issue) as one of the variables and various scales and measures were applied for possible identification of a subtype of mothers. Consequently, more than $30 \%$ of the mothers was identified as resilient due to the lowest scores on various measures such as stressful situations and avoidant coping and they had fewest symptoms, including PTSD and anger when compared to the rest of the participants. Another group, 
labelled avoidant coping mothers, also made up one third of all the participants in the same study. Although the avoidant coping mothers reported a moderate level of PTSD symptoms and a low level of anger and neuroticism, they had a markedly higher level of avoidant coping. Other factors such as secondary victimisation, shame and self-blame might limit mothers' ability to receive support, which in turn could bring about the failure to develop effective coping skills (see Kilroy et al. 2014; Toledo and Seymour 2016).

Social isolation was another way of coping with the overwhelming effects of CSA. Both Dyb et al. (2003) and Kilroy et al. (2014) reported that non-abusing caregivers who experienced difficulty coping with the reality of CSA isolated themselves from social life. Furthermore, Toledo and Seymour (2016) found that isolation from extended family members was a common issue among $40 \%$ of their Australian families, mainly containing non-abusing mothers.

Various researchers point to the possibility that secondary traumatisation or shame could enhance the likelihood of self-isolation or social withdrawal. Masilo and Davhana-Maselesele (2016) found that non-abusing mothers were afraid of being judged by others for not fulfilling their caregiving responsibility and consequently isolated themselves by keeping their child away from abusive environments. This is consistent with McCallum (2001), who emphasised the relationship between self-isolation and shame. The author proposed that feeling shame is likely to enhance the level of self-isolation, in turn hindering women from accessing sources of support.

Both non-abusing mothers and service providers mentioned the importance of mothers learning how to interact with their sexually abused child, whereas only mothers mentioned wanting to learn about the psychological and potential long-term impact of CSA and how to cope with these problems. Interestingly, only therapists stressed that mothers need to learn self-care, emotion regulation and communication skills (Han and Kim 2016). In contrast, Kilroy et al. (2014) found that self-care was 
adopted among non-abusing caregivers as one way of coping and that other coping skills, such as being in contact with people related to the abuse, and using therapeutic means, as found by Han and Kim's (2016) were also important. In sum, non-abusing mothers, tend to sacrifice themselves on behalf of their abused children, often neglecting their own needs (see Carvalho et al. 2009; Toledo and Seymour 2016).

\section{Conclusion and Implications for Research}

This narrative review aimed to find out how non-abusing mothers' need for support is recognised -in the recent literature- in their responses to CSA disclosure. Despite the fact that most of the reviewed studies were qualitative in design, the review provides valuable knowledge for comprehending nonabusing mothers' own support needs after CSA disclosure. The review process yielded four themes: improving the quality of whole social support network for non-abusing mothers; being blamed, maternal guilt and shame; anger; and coping strategies.

The first theme, related to improving the whole social support network for mothers underlines the significance of the quality of the relationship between non-abusing mothers and professionals, as well as between mothers and informal sources of support (such as family, friends and other community members). Caregiving adults, mostly non-abusing mothers, defined "being supportive and welcoming, having sufficient knowledge on the issue, empathic understanding and provision of necessary resources" as the main elements of a good-quality relationship with human services professionals (e.g. Alaggia 2001 and Kilroy et al. 2014).

It is important to note that not only formal support, but also informal support should be improved as the literature demonstrates that family or friends might not be understanding or welcoming when they encounter this problem. With respect to support from family members, it is quite common that mothers feel blamed, judged and not understood, especially in intrafamilial cases of CSA (e.g. 
Levenson et al. 2012; Kilroy et al. 2014; Toledo and Seymour 2016). Campaigns could be useful for increasing the level of public awareness on CSA so that not only professionals, but also members of non-abusing mothers' close environment know how to approach and communicate with them. Moreover, feelings of self-blame and shame, anger and isolation might be alleviated if the nonabusing mothers of sexually abused children are invited to participate in support groups in which caregiving adults with similar experiences of CSA share events in their lives (e.g. Masilo and Davhana-Maselesele 2016).

Regarding the review's second theme, non-abusing mothers tend to blame themselves, are blamed by others or feel ashamed, despite the obvious fact that the abuser is responsible for the CSA. Various reasons can be offered for this, such as maternal sense of failure to protect the child or not being able to stop the abuse, not being aware of the abuse or ignoring the warning signs (e.g. McCallum 2001; Mayekiso and Mbokazi 2007; Pretorius et al. 2011). It is vital to remember that cultural norms, such as responsibility of keeping their family intact (see Alaggia 2001), are embedded in women's mothering roles, and consequently that feelings of self-blame, shame or secondary victimisation associated with "the myth of perfect motherhood" can lead women to sacrifice themselves and underestimate their own needs on behalf of their children's (see Carvalho et al. 2009).

An association was observed between "anger" and "being blamed, maternal guilt and shame”. Anger, the third theme identified in the data, is a reaction which mothers may direct towards professionals, partners, family members, friends, their sexually abused child or even themselves. Non-abusing mothers expressed anger in situations in which professionals blamed them, did not act on the issue appropriately or did not appear understanding (e.g. Mayekiso and Mbokazi 2007; Kilroy et al. 2014). Moreover, in situations where the abuser was the father figure or the abuse was intrafamilial, the mothers were likely to direct their anger towards themselves, their partner or other non-abusing 
family members. Maternal guilt and self-anger seemed to be related to the mother's sense of failure in protecting her child and holding herself responsible for what had happened (e.g. McCallum 2001; Levenson et al. 2012; Pretorius et al. 2011; Han and Kim 2016).

The last theme, coping strategies, while only a latent topic in the reviewed literature, pointed to the need for empowering non-abusing mothers of sexually abused children. The mothers tend to be emotionally overwhelmed when they experience CSA disclosure, a response that could hinder their adoption of effective coping skills (e.g. McCallum 2001; Mayekiso and Mbokazi 2007; Masilo and Maselesele 2016; Pretorius et al. 2011). The reviewed research revealed the coping strategies adopted by non-abusing mothers, such as avoidance, social isolation, religion or improving knowledge on CSA or on parenting skills to deal with CSA (e.g. McCallum 2001; Dyb et al. 2003; Cyr et al. 2013).

These four themes aside, several issues merit further consideration. These include the difficulty of measuring support, the fact that the overwhelming majority of the cases were intrafamilial, and the importance of encouraging the voices of non-abusing mothers to be heard as women.

Some researchers might profile mothers as, for example, "supportive and unsupportive" based on their life history and the quality of their interaction with their sexually abused children (e.g. Alaggia 2001; Cyr et al. 2013). Moreover, it should be remembered that the concept of support is usually portrayed as child-focused, is problematic and is pointed out by various researchers in the recent literature (e.g. Bolen 2002b; Dyb et al. 2003; Cyr et al. 2013; Bolen et al. 2015). The difficulty of measuring support is associated with a lack of standardised measures, variations in the definition and boundaries of support and the use of data based on retrospective self-reports. Therefore, readers must be aware of these limitations and they should regard such classifications as tentative only.

There also appears to be a gap in the research on maternal experiences based on extrafamilial CSA cases. Most of the existing research only addresses intrafamilial cases of CSA (e.g. Alaggia 2001; 
Mayekiso and Mbokazi 2007; Levenson et al. 2012) while relatively little work has been done on the parental experiences of children who have been sexually abused outside of the family (e.g. Dyb et al. 2003). The experiences of mothers may diverge or converge according to their relationship with the perpetrator. Therefore, further research on the support needs of non-abusing mothers in cases of extrafamilial CSA cases is crucial. Improving knowledge on this category of the abuse will help researchers and audience better understand if and how maternal reactions such as anger, self-blame or shame, secondary victimization, their needs and coping skills demonstrate similarities or differences when compared to the findings of research on intrafamilial cases of CSA.

Researchers should carefully re-consider the way they investigate the concept "support" and address non-abusing mothers' own support needs. This review shows that perceived support of non-abusing mothers was only investigated with the aim of finding out if this affects the quality of the support they provide for their children (see Elliot and Carnes 2001 for a review). However, mothers' own need for support, if only for the sake of themselves as women, independently of their mothering role and the heteronormative expectations of society, were largely overlooked in the current CSA literature. Furthermore, it is apparent that the current heteronormative discourses embedded in culture dictate that women and sexually abused children maintain secrecy about the abuse. When women are silenced by the impact of secondary victimization and self-blame, this situation hinders them from seeking support for themselves (see McCallum 2001; McLaren 2013; Masilo and Maselesele 2016).

When mothers' needs were investigated, it was interesting to note that they usually referred to the need of developing coping skills in relation to the needs of their children, frequently ignoring their own needs such as self-care, emotion regulation and communication skills (see Kilroy et al. 2014; Han and Kim 2016; Toledo and Seymour 2016). Therefore, the provision of appropriate professional 
services (e.g. creating a safe space for listening, therapy and empowering women by enhancing their psychosocial resources) for non-abusing mothers and other non-abusing family members is also vital.

In conclusion, it is hoped that this narrative review will encourage researchers to work on the personal support needs of women who are overwhelmed with the trauma caused by CSA disclosure. Awareness that all the themes are intertwined, might render it rewarding to work on the relationship between the maternal need of support and other aspects such as secondary victimisation or selfblame, anger and self-isolation after CSA disclosure. Empowering these mothers and developing their support network could help shift the burden of bearing the responsibility for CSA from themselves while enabling them to develop better strategies for coping with the devastating effects of CSA. In this way, their functioning as women and as mothers will be enhanced. 


\section{References}

Alaggia, R. (2001) Cultural and religious influences in maternal response to intrafamilial child sexual abuse: Charting new territory for research and treatment. Journal of Child Sexual Abuse, 10 (2), 41-60.

Alaggia, R. (2004) Many ways of telling: expanding conceptualizations of child sexual abuse disclosure. Child Abuse \& Neglect, 28, 1213-1227.

Berliner, L., \& Elliott, D. M. (2002). Sexual abuse of children. In J. E. B. Myers, L. Berliner, J. Briere, C. T. Hendrix, C. Jenny, \& T. A. Reid (Eds.), The APSAC handbook on child maltreatment (2nd ed., 55-78). Thousand Oaks, CA: Sage.

Bolen, R. M. (2002a) Guardian support of sexually abused children: A study of its predictors. Child Maltreatment, 7 (3), 265-276.

Bolen, R. M. (2002b) Guardian support of sexually abused children. A definition in search of a construct. Trauma, Violence \& Abuse, 3 (1), 40-67.

Bolen, R. M., Dessel, A. B. \& Sutter, J. (2015) Parents will be parents: Conceptualizing and measuring nonoffending parent and other caregiver support following disclosure of sexual abuse. Journal of Aggression, Maltreatment \& Trauma, 24 (1), 41-67.

Bolen, R. M. \& Gergely, K. B. (2015) A meta-analytic review of the relationship between nonoffending caregiver support and postdisclosure functioning in sexually abused children. Trauma, Violence, \& Abuse, 16 (3), 258-279.

Carvalho, Q. C. M. (2009) Child sexual abuse: The perception of mothers concerning their daughters' sexual abuse. Abuso sexual infantil: percepción de las madres frente al abuso sexual de sus 
hijas abuso sexual infantil: percepção de mães em face do abuso sexual de suas filhas. Revista Latino-Americana de Enfermagem, 17 (4), 501-506.

Crawford, S. L. (1999) Intrafamilial sexual abuse: What we think we know about mothers and implications for intervention. Journal of Child Sexual Abuse, 7 (3), 55-72.

Cyr, M., McDuff, P. \& Hebert, M. (2013) Support and profiles of nonoffending mothers of sexually abused children. Journal of Child Sexual Abuse, 22 (2), 209-230.

Dyb, G., Holen, A. , Steinberg, A. , Rodriguez, N. \& Pynoos, R. S. (2003) Alleged sexual abuse at a day care center: Impact on parents. Child Abuse and Neglect, 27 (8), 939-950.

Ehrmin, J. T. (1996) No more mother blaming: A feminist nursing perspective on the mother's role in father-daughter incest. Archives of Psychiatric Nursing, 10 (4), 252-260.

Elliott, A. \& Carnes, C. (2001) Reactions of nonoffending parents to the sexual abuse of their child: A review of the literature. Child Maltreatment, 6 (4), 314-331.

Finfgeld-Connett, D. \& Johnson, E. D. (2012). Literature search strategies for conducting knowledge-building and theory-generating qualitative systematic reviews. Journal of Advanced Nursing, 69 (1), 194-204.

Han, S. \& Kim, J. (2016) Perceived needs for support program for family with child sexual abuse victim in South Korea: Focus group interview with therapist and mothers. Journal of Child Sexual Abuse, 25 (7), 738-756.

Knott, T. \& Fabre, A. (2014) Maternal response to the disclosure of child sexual abuse: Systematic review and critical analysis of the literature. Issues in Child Abuse Accusations, 20, p. N_A. 
Jensen, T. K., Gulbrandsen, W., Mossige, S., Reichelt, S. \& Tjersland, O. A. (2005) Reporting possible sexual abuse: A qualitative study on children's perspectives and the context for disclosure. Child Abuse \& Neglect, 29, 1395-1413.

Kilroy, S. J., Egan, J., Maliszewska, A. \& Sarma, K. M. (2014) "Systemic Trauma": The impact on parents whose children have experienced sexual abuse. Journal of Child Sexual Abuse, 23, 481503.

Levenson, J. S., Tewksbury, R. \& DiGiorgio-Miller, J. (2012) Experiences of non-abusing parents and caretakers in child sexual abuse cases. The Southwest Journal of Criminal Justice, 8 (2), 179-185.

Lovett, B.B. (2004) Child sexual abuse disclosure: maternal response and other variables impacting the victim. Child \& Adolescent Social Work Journal, 21 (4), 355-371.

Masilo, G. \& Davhana-Maselesele, M. (2016) Experiences of mothers of sexually abused children in North-West province, post disclosure. Curationis, 39 (1), 1-9.

Mayekiso, T. \& Mbokazi, F. (2007) 'Maternal response to father-daughter incest: Experiences of mothers following disclosure'. Journal of Psychology in Africa, 17 (1-2), 51-56.

Mays, N., Pope, C. \& Popay, J. (2005). Systematically reviewing qualitative and quantitative evidence to inform management and policy-making in the health field. Journal of Health Services Research \& Policy, 10 (1), 6-20.

McCallum, S. (2001) Nonoffending mothers: An exploratory study of mothers whose partners sexually assaulted their children. Violence Against Women, 7 (3), 315-334.

McLaren, H. J. (2013) (Un)-blaming mothers whose partners sexually abuse children: In view of heteronormative myths, pressures and authorities. Child \& Family Social Work, 18 (4), 439448. 
Paine, M. L. \& Hansen, D. J. (2002) Factors influencing children to self-disclose sexual abuse. Clinical Psychology Review, 22 (2), 271-295.

Pereda, N., Guilera, G., Forns, M. \& Gomez-Benito, J.(2009) The international epidemiology of child sexual abuse: a continuation of Finkelhor (1994). Child Abuse Neglect, 33 (6), 331-342.

Pretorius, G., Chauke, A. P. \& Morgan, B. (2011) The lived experiences of mothers whose children were sexually abused by their intimate male partners. Indo-Pacific Journal of Phenomenology, $11(1), 1-14$.

Starzynski, L. L., Ullman, S. E., Filipas, H. H., \& Townsend, S. M. (2005). Correlates of women's sexual assault disclosure to informal and formal support sources. Violence and Victims, 20 (4), 417-32.

Stoltenborgh, M., van Ijzendoorn M. H., Euser, E. M. \& Bakermans-Kranenburg, M. J. (2011) A global perspective on child sexual abuse: meta-analysis of prevalence around the world. Child Maltreatment, 16 (2), 79-101.

Tamraz, D. N. (1996) Nonoffending mothers of sexually abused children: Comparison of opinions and research. Journal of Child Sexual Abuse, 5 (4), 75-104.

Womack, M. E. (1999) Helping mothers in incestuous families: An empathic approach. Women \& Therapy, 22 (4), 17-34.

Toledo, A. \& Seymour, F. (2013) Interventions for caregivers of children who disclose sexual abuse: A review. Clinical Psychology Review, 33 (6), 772-781.

Toledo, A. \& Seymour, F. (2016) Caregiver needs following disclosure of child sexual abuse. Journal of Child Sexual Abuse, 25 (4), 403-414.

WHO

Child

Maltreatment.

Retrieved

from

http://www.who.int/mediacentre/factsheets/fs150/en/ (Accessed: 20.03.2015, 15.40 pm). 


\begin{tabular}{|c|c|c|c|c|c|c|}
\hline Author/s & Country & Aim & $\begin{array}{l}\text { Type of } \\
\text { CSA }^{1}\end{array}$ & $\begin{array}{l}\text { Sample and } \\
\text { Recruitment }\end{array}$ & Methodology & Emerging Themes \\
\hline $\begin{array}{l}\text { Alaggia } \\
(2001)\end{array}$ & Canada & $\begin{array}{l}\text { To } \\
\text { understand } \\
\text { how non- } \\
\text { abusing } \\
\text { mothers } \\
\text { responded } \\
\text { emotionally } \\
\text { and } \\
\text { behaviourally } \\
\text { to disclosure } \\
\text { in relation to } \\
\text { cultural } \\
\text { context. }\end{array}$ & Intra- & $\begin{array}{l}\text { Ten mothers } \\
\text { participating in a } \\
\text { psycho-education } \\
\text { group organised } \\
\text { by agencies } \\
\text { working with } \\
\text { sexually abused } \\
\text { children. }\end{array}$ & $\begin{array}{l}\text { Qualitative, } \\
\text { in-depth } \\
\text { interview } \\
\text { guide, } \\
\text { discovery- } \\
\text { oriented } \\
\text { approach }\end{array}$ & $\begin{array}{l}\text { Improving the quality of whole social } \\
\text { support network for non-abusing } \\
\text { mothers } \\
\text { Being blamed, maternal guilt and shame } \\
\text { Coping strategies }\end{array}$ \\
\hline $\begin{array}{l}\text { Cyr et al. } \\
(2013)\end{array}$ & Canada & $\begin{array}{l}\text { To examine } \\
\text { how profiles }\end{array}$ & Both & $\begin{array}{l}226 \text { non-abusing } \\
\text { mothers recruited }\end{array}$ & $\begin{array}{l}\text { Quantitative, } \\
\text { person- }\end{array}$ & $\begin{array}{l}\text { Improving the quality of whole social } \\
\text { support network for non-abusing }\end{array}$ \\
\hline
\end{tabular}


of

non-abusing

mothers

could better

describe their

ability to

support their

children after

disclosure.

\begin{tabular}{|c|c|c|}
\hline $\begin{array}{l}\text { Dyb et al. } \\
(2003)\end{array}$ & Norway & $\begin{array}{l}\text { To describe } \\
\text { the cascade } \\
\text { of stressful } \\
\text { events and } \\
\text { secondary } \\
\text { life changes } \\
\text { experienced } \\
\text { by parents in } \\
\text { a case of } \\
\text { alleged } \\
\text { sexual abuse } \\
\text { in a day care } \\
\text { programme. }\end{array}$ \\
\hline
\end{tabular}

Han and Kim Korea (2016)

$\begin{array}{lll}\text { via child } & \text { centred } & \text { mothers } \\ \text { protection } & \text { approach, } & \text { Coping strategies } \\ \text { services. } & \text { various types } & \text { Anger } \\ & \text { of scales, } & \\ & \text { indexes and } & \\ & \text { questionnaires } & \end{array}$

Extra- 24 non-abusing mothers and 15 non-abusing fathers who were registered in a treatment

Quantitative, face-to-face interviews, self-report measures and a series of programme. questionnaires

\author{
Improving the quality of whole social \\ support network for non-abusing \\ mothers \\ Coping strategies
}
To
investigate
the
perspectives
of non-
abusing
mothers of
sexually

$\begin{array}{ll}\text { Not } & \text { Four non- } \\ \text { stated } & \text { abusing mothers } \\ & \text { and five } \\ & \text { professionals } \\ & \text { were recruited } \\ & \text { via a support } \\ & \text { centre and } \\ & \text { government- }\end{array}$

Qualitative, focus group interviews conducted with nonabusing mothers and professionals.
Improving the quality of whole social support network for non-abusing mothers

Being blamed, maternal guilt and shame Anger Coping strategies 
abused

children and

therapists

about what

family

support

programs

were needed.

\begin{tabular}{|c|c|c|}
\hline $\begin{array}{l}\text { Kilroy et al. } \\
(2014)\end{array}$ & Ireland & $\begin{array}{l}\text { To } \\
\text { understand } \\
\text { how parents } \\
\text { were affected } \\
\text { and what } \\
\text { their } \\
\text { experiences } \\
\text { were once } \\
\text { they learned } \\
\text { of the CSA. }\end{array}$ \\
\hline $\begin{array}{l}\text { Levenson et } \\
\text { al. (2012) }\end{array}$ & USA & $\begin{array}{l}\text { To better } \\
\text { understand } \\
\text { the unique } \\
\text { experiences } \\
\text { of non- } \\
\text { abusing } \\
\text { caretakers } \\
\text { who also } \\
\text { identify } \\
\text { themselves as } \\
\text { closely } \\
\text { related to the }\end{array}$ \\
\hline
\end{tabular}

funded agency, respectively.
Qualitative, Improving the quality of whole social semistructured interviews biological and registered via a specialist CSA service providing parenting support.

26 female and five male caregivers were registered via completing an online survey on four different websites that provide support for non-abusing family members of registered sex support network for non-abusing mothers

Being blamed, maternal guilt and shame Coping strategies

Anger
Quantitative, Improving the quality of whole social Online survey support network for non-abusing mothers Being blamed, maternal guilt and shame Anger 
abuser of the

child.

\begin{tabular}{|c|c|c|c|c|}
\hline $\begin{array}{l}\text { Masilo and } \\
\text { Davhana- } \\
\text { Maselesele } \\
(2016)\end{array}$ & $\begin{array}{l}\text { South } \\
\text { Africa }\end{array}$ & $\begin{array}{l}\text { To explore } \\
\text { and describe } \\
\text { the } \\
\text { experiences } \\
\text { of mothers of } \\
\text { sexually } \\
\text { abused } \\
\text { children. }\end{array}$ & $\begin{array}{l}\text { Includes } \\
\text { intra- but } \\
\text { not } \\
\text { clearly } \\
\text { stated if } \\
\text { also } \\
\text { extra- is } \\
\text { involved. }\end{array}$ & $\begin{array}{l}17 \text { non-abusing } \\
\text { mothers } \\
\text { registered via } \\
\text { care centres } \\
\text { helping sexually } \\
\text { abused children. }\end{array}$ \\
\hline
\end{tabular}

\begin{tabular}{|c|c|c|}
\hline $\begin{array}{l}\text { Mayekiso } \\
\text { and Mbokazi } \\
(2007)\end{array}$ & $\begin{array}{l}\text { South } \\
\text { Africa }\end{array}$ & $\begin{array}{l}\text { To explore } \\
\text { the impact of } \\
\text { disclosure of } \\
\text { sexual abuse } \\
\text { of daughter } \\
\text { by the father } \\
\text { or father } \\
\text { figure on } \\
\text { mother. }\end{array}$ \\
\hline
\end{tabular}

$\begin{array}{ll}\text { McCallum Australia } & \text { To outline Intra- } \\ & \text { the } \\ & \text { experiences } \\ & \text { of women } \\ & \text { from the } \\ & \text { point of } \\ & \text { disclosure of } \\ & \text { their child's }\end{array}$

offenders.

Qualitative, Improving the quality of whole social

exploratory, support network for non-abusing

descriptive mothers

and

Being blamed, maternal guilt and shame

contextual, Coping Strategies

unstructured Anger

in-depth

interviews and

field notes

Seven non-

abusing mothers

registered via

agencies serving

for sexually

abused children.

Qualititative, Improving the quality of whole social

exploratory, support network for non-abusing

semi-

mothers

structured

interviews

Being blamed, maternal guilt and shame Anger

Qualitative, unstructured interviews, grounded theory

Improving the quality of whole social abusing mothers registered via a child protection agency. support network for non-abusing mothers

Being blamed, maternal guilt and shame Coping strategies

Anger 
sexual abuse.

\begin{tabular}{|c|c|c|c|c|c|c|}
\hline $\begin{array}{l}\text { Pretorius et } \\
\text { al. (2011) }\end{array}$ & $\begin{array}{l}\text { South } \\
\text { Africa }\end{array}$ & $\begin{array}{l}\text { To explore } \\
\text { the lived } \\
\text { experiences } \\
\text { of mothers } \\
\text { whose } \\
\text { children were } \\
\text { sexually } \\
\text { abused by } \\
\text { their intimate } \\
\text { male } \\
\text { partners. }\end{array}$ & Intra- & $\begin{array}{l}\text { Three non- } \\
\text { abusing mothers } \\
\text { registered via } \\
\text { child abuse } \\
\text { treatment centre. }\end{array}$ & $\begin{array}{l}\text { Qualitative, } \\
\text { explorative, } \\
\text { descriptive } \\
\text { and inductive } \\
\text { in nature, } \\
\text { unstructured } \\
\text { interviews, } \\
\text { with open- } \\
\text { ended } \\
\text { questions }\end{array}$ & $\begin{array}{l}\text { Improving the quality of whole social } \\
\text { support network for non-abusing } \\
\text { mothers } \\
\text { Being blamed, maternal guilt and shame } \\
\text { Anger }\end{array}$ \\
\hline $\begin{array}{l}\text { Toledo and } \\
\text { Seymour } \\
(2016)\end{array}$ & Australia & $\begin{array}{l}\text { Investigating } \\
\text { the impact of } \\
\text { CSA } \\
\text { disclosure } \\
\text { and } \\
\text { associated } \\
\text { needs as } \\
\text { identified by } \\
\text { caregivers. }\end{array}$ & $\begin{array}{l}\text { Both } \\
(50 \% \\
\text { intra })\end{array}$ & $\begin{array}{l}\text { Non-abusing } \\
\text { caregivers from } 59 \\
\text { families involving } \\
62 \text { children filled } \\
\text { in needs } \\
\text { assessment forms. } \\
\text { They were } \\
\text { recruited by a } \\
\text { centre providing } \\
\text { parenting support, } \\
\text { and } 70 \% \text { of } \\
\text { caregivers were } \\
\text { mothers. }\end{array}$ & $\begin{array}{l}\text { Mixed } \\
\text { Methods, a } \\
\text { needs } \\
\text { assessment } \\
\text { form } \\
\text { involving } \\
\text { open-ended } \\
\text { and scale } \\
\text { questions }\end{array}$ & $\begin{array}{l}\text { Improving the quality of whole social } \\
\text { support network for non-abusing } \\
\text { mothers } \\
\text { Coping strategies }\end{array}$ \\
\hline
\end{tabular}

Table 1 Information on Reviewed Articles 


\section{Figure Legends}

Figure 1. Review Process

\section{Table Legends}

Table 1. Information on Reviewed Articles 